\title{
l-Triiodothyronine: Is this Peripheral Hormone a Central Neurotransmitter?
}

\author{
Corge A. Mason, Ph.D., Cheryl H. Walker, B.A., and Arthur J. Prange, Jr., M.D.
}

Iminodothyronine $\left(T_{3}\right)$ has previously been shown to ance fast-phase, depolarization-induced ${ }^{45} \mathrm{Ca}$ uptake - H. poposomes at low nanomolar concentrations sumable to those reported for whole brain. fortheless, the physiologic importance of these suclear-mediated effects of $T_{3}$ has remained uncertain, ant because specific mechanisms and the presence of lid presumptive sites of action have not been benstrated.

lsotopic studies showing that L-tetraiodothyronine xyorine, $\left.T_{4}\right)$ and $T_{3}$ are concentrated in synaptosomes, dhat $T_{4}$ is deiodinated to $T_{3}$ suggested that benous levels of $T_{3}$ in nerve terminals are probably much higher than in other compartments of the brain. In the present study we confirmed that endogenous levels of $T_{3}$ in nerve terminals are at least eightfold higher, and may be as much as 60-fold higher, than in whole brain. More importantly, we showed that both ${ }^{125}$ I-labeled $T_{3}$ and endogenous $T_{3}$, but not ${ }^{125} I-T_{4}$ or endogenous $T_{4}$, are released from depolarized synaptosomes, primarily by a $\mathrm{Ca}^{2+}$-dependent process. This demonstrates a mechanism for raising the level of $T_{3}$ within the synapse, where the hormone may interact with pre- and postsynaptic binding (or uptake) sites, and suggests that the peripheral hormone $T_{3}$ may be a neurotransmitter.

[Neuropsychopharmacology 8:253-258, 1993] or worDs: Synaptosome; Thyroid hormones; Release; artusion; Rat

wof the known effects of thyroid hormones, particon growth, development, and structural mainmence of the central nervous system, are thought to initiated by the binding of L-triiodothyronine $\left(\mathrm{T}_{3}\right)$ maclear receptors, which regulate protein synthesis Oppenheimer 1979; Sterling 1979). However, in the mpptosome model of the nerve terminal, thyroid hormes also have been shown to alter some of the pesses that mediate synaptic transmission (Mason ad. 1987, 1990; Hashimoto et al. 1991). Radiolabeled

\footnotetext{
fin the Department of Psychiatry (GAM, AJP) and the Brain and dupment Research Center (GAM, CHW, AJP), School of Media University of North Carolina at Chapel Hill, Chapel Hill, North Cosina 27599.

Hess reprint requests to: George A. Mason, Ph.D., Department andiatry, CB\#7160, School of Medicine, University of North Carobuchapel Hill, Chapel Hill, North Carolina 27599.

meved March 3, 1992; revised June 30, 1992 and August 26, 1992; Teptember 11, 1992.
}

thyroid hormones that enter the brain are concentrated in synaptosomes (Dratman et al. 1976; Dratman and Crutchfield 1978), where L-tetraiodothyronine (thyroxine, $T_{4}$ ) is converted to $T_{3}$, a more active metabolite (Dratman and Crutchfield 1978), and $\mathrm{T}_{3}$ is degraded to $\mathrm{T}_{2}$ (Tanaka et al. 1981).

Recent work indicates that $T_{3}$ is taken up by two kinetically distinct active transport systems, whereas $\mathrm{T}_{4}$ enters the synaptosome by diffusion (Kastellakis and Valcana 1989). Specific binding sites for $\mathrm{T}_{3}$ on synaptosomes and synaptic membranesfrom ratbrain have also been described (Mashio et al. 1982, 1983). The clinical observation that small concurrent doses of $\mathrm{T}_{3}$ augment the therapeutic actions of tricyclic antidepressants in apparently euthyroid depressed patients (Prange et al. 1969; Goodwin et al. 1982; Schwarcz et al. 1984) is likewise consistent with the concept of the nonnuclear brain effects of thyroid hormones because the nuclear $\mathrm{T}_{3}$ receptors in the brains of these patients would be expected to be fully occupied (Crantz et al. 1982) before $\mathrm{T}_{3}$ was given. 
Although the evidence supporting direct actions of thyroid hormones on synaptic processes is compelling, there has been no clear, comprehensive conceptual framework within which to evaluate its physiologic relevance. It has been shown that concentrations of thyroid hormones in rat whole brain are in the low nanomolar range (Dratman et al. 1983), but hormone concentrations in presynaptic terminals and the synaptic cleft are uncertain, and the dynamics of thyroid hormone levels in this complex anatomic area are poorly understood.

In the present study we confirmed earlier isotopic studies indicating that $T_{3}$ levels in rat brain synaptosomes are much higher than whole brain levels. Perhaps more importantly, we show that endogenous $T_{3}$, but not $\mathrm{T}_{4}$, can be released from depolarized synaptosomes by a $\mathrm{Ca}^{2+}$-dependent process like the classic neurotransmitters. This demonstrates a mechanism for raising the levels of $T_{3}$ within the synapse where the hormone can potentially interact with pre- and postsynaptic binding (or uptake) sites.

\section{MATERIALS AND METHODS}

\section{Animals}

All experiments were performed with brain tissue preparations from adult male Sprague-Dawley rats (Charles River Breeding Laboratories, Wilmington, MA) weighing at least $200 \mathrm{~g}$. A total of 22 rats was used in this study: four for determinations of hormone levels in whole brain, four for determinations of hormone levels in synaptosomes, eight for determinations of the release experiments with radiolabeled hormones, and six for determinations of endogenous hormone release (see below). They were housed two to a cage and given free access to laboratory chow and water. Animal quarters were kept at temperature of between 22 and $25^{\circ} \mathrm{C}$, and the light-dark cycle was 12 hours.

\section{Preparation of Tissue Homogenates}

The brains of experimental animals killed by decapitation were removed immediately and kept on ice while the cerebral cortex was dissected and weighed. Cortical tissue was homogenized in 10 volumes of $0.32 \mathrm{~mol} / \mathrm{L}$ sucrosecontaining $3 \mu \mathrm{mol} / \mathrm{Liopanoic}$ acid to inhibit thyroid hormone metabolism, and centrifuged for 10 minutes at $800 \times 8$ to remove nuclei and cell debris. The synaptosome-containing supernatant (protein concentration, about $700 \mu \mathrm{g} / 100 \mu \mathrm{l}$ ) was used in the release assay.

\section{Preparation of Synaptosomes}

Synaptosomes were prepared from the cerebral cortex by the procedure of Dodd et al. (1981). The cortex was homogenized in 10 volumes of $0.32 \mathrm{~mol} / \mathrm{L}$ sucrose immediately after dissection and centrifuged for 10 minutes at $800 \times g$. The resulting supernatant was then layered onto $1.2 \mathrm{~mol} / \mathrm{L}$ sucrose and centrifuged at about $178,000 \times g$ for 30 minutes using a Beckman 60 Ti fixedangle rotor. Synaptosomes were collected at the interface between the $0.32 \mathrm{~mol} / \mathrm{L}$ and $1.2 \mathrm{~mol} / \mathrm{L}$ sucrose, diluted $1: 2.5$ with $0.32 \mathrm{~mol} / \mathrm{L}$ sucrose and layered onto 1 volume (original homogenate) of $0.8 \mathrm{~mol} / \mathrm{L}$ sucrose. The pellet from the first spin containing cell debris and nuclear material, the mitochondrial pellet from the first high-speed spin, and the synaptosomal pellet from a second 30 -minute centrifugation at $178,000 \times g$ were subjected to thyroid hormone extraction described below. In some experiments, the sucrose solutions contained $1 \mathrm{nmol} / \mathrm{L} \mathrm{T}_{3}$, the approximate concentration in whole brain, and only the synaptosomal pellet was extracted. This was done to simulate the in vivo condition in which additional hormone is available to replace that lost from the synaptosomes by diffusion or other processes. Protein concentrations were later determined by the method of Lowry et al. (1951).

\section{Superfusion System}

Thyroid hormone release was studied with a twochannel or chamber superfusion system previously used to study neurotransmitter release (Hashimoto et al. 1991). A superfusion technique was chosen over a vacuum filtration or centrifugation method to avoid the potential problems of interpretation associated with the reuptake of hormones. The superfusion apparatus consisted of two Acrodisc disposable filter assemblies $(0.45-\mu$ pore size, Gelman Sciences Inc., Ann Arbor, MI), which served as superfusion chambers. All buffer vessels and the two superfusion chambers, which were used simultaneously, were submerged in a $37^{\circ} \mathrm{C}$ constant-temperature water bath during each run. The chamber inlets were connected to an adjustable flow ISCO WIZ multichannel peristaltic pump (Gilson Inc., Middleton, WI). Three-way valves (American Pharmaseal Co., American Hospital Corp., Valencia, CA) were used to switch from wash to release buffer (see below) and vice versa without disrupting flow or introducing air bubbles into the closed system. Buffers were pumped through the chambers at a flow rate of $1 \mathrm{ml} /$ min, and fractions of the superfusate from the chambers were collected at 1-minute intervals, using an ISCO Retriever II fractionator, into either borosilicate glass tubes or $12 \times 75-\mathrm{mm}$ antibody-coated radioimmunoassay (RIA) tubes (see below). The ${ }^{125} I_{-} T_{3}$ and ${ }^{125} I_{-} T_{4}$ were counted in an LKB 1272 Clinigamma gamma counter at an efficiency of $70 \%$.

For some experiments, fresh synaptosome-containing homogenates were preloaded with ${ }^{125} \mathrm{I}-\mathrm{T}_{3}$ or ${ }^{125} \mathrm{I}_{-} \mathrm{T}_{4}(3 \mathrm{nmol} / \mathrm{L})$ by incubation for 25 minutes at $37^{\circ} \mathrm{C}$ with superfusion wash buffer $(135 \mathrm{mmol} / \mathrm{L} \mathrm{NaCl}, 5$ 
amol/ $\mathrm{LCl}, 1.4 \mathrm{mmol} / \mathrm{L} \mathrm{MgSO} 4,25 \mathrm{mmol} / \mathrm{L}$ glucose, $3 \mathrm{mmol} / \mathrm{L} \mathrm{CaCl} 2, \mathrm{pH}$ 7.4). Preparations preloaded with ${ }^{4}-\mathrm{T}_{3}$ or ${ }^{125} \mathrm{I}-\mathrm{T}_{4}$ were simultaneously drawn by the peristaltic pump into both superfusion chambers and spertused with wash buffer for 4 minutes at a flow rate $\mathrm{d} 2 \mathrm{~m} / \mathrm{min}$, and then for 3 minutes at a rate of $1 \mathrm{ml} / \mathrm{min}$. The collection of $1 \mathrm{ml}$ portions of the perfusate was begun at this time and continued throughout the release way. Homogenates that were not preloaded with ${ }^{125} \mathrm{I}$ beled hormones were not superfused with wash bebre collection of fractions began.

In the first set of experiments, ${ }^{125} \mathrm{I}_{-} \mathrm{T}_{3}$ or ${ }^{125} \mathrm{I}_{-} \mathrm{T}_{4}$ boded tissues in the two chambers were exposed to ligh $\mathrm{K}^{+}$release buffer in the presence or absence of $\mathrm{Ca}^{2+}$. The $\mathrm{Ca}^{2+}$ was used as a variable because inpolarization-induced release of neurotransmitters fom nerve terminals is generally thought to be dependent upon the rapid entry of $\mathrm{Ca}^{2+}$ through voltageensitive channels (Augustine et al. 1987). The release buffer was identical to the wash buffer except that it ontained $80 \mathrm{mmol} / \mathrm{L} \mathrm{NaCl}, 55 \mathrm{mmol} / \mathrm{L} \mathrm{KCl}$, and no $\mathrm{M}_{8} \mathrm{SO}_{4}$. In the second set of experiments, depolarizaion-induced release of endogenous $T_{3}$ and $T_{4}$ in the presence and absence of $\mathrm{Ca}$ was measured by RIA.

\section{Bedioimmunoassay of $T_{3}$ and $T_{4}$}

following extraction as described by Nejad et al. (1975), $T_{3}$ and $T_{4}$ in homogenates of whole brain or synaptosones purified from cerebral cortex were measured using commercially available reagent kits (BectonDickinson Immunodiagnostics, Orangeburg, NY). Extrats were dried down with $\mathrm{N}_{2}$ and diluted with " 0 " standard, and standards were diluted 1:1 with blank atracts (containing no $\mathrm{T}_{3}$ or $\mathrm{T}_{4}$ ); otherwise, assays were performed according to kit protocols. The firiency of the extraction was greater than $75 \%$ for both hormones. The sensitivities and the interassay coefficents of variation for the $\mathrm{T}_{3}$ and $\mathrm{T}_{4}$ assays were $4.9 \mathrm{pg} /$ whe and $95 \mathrm{pg} /$ tube, and $8 \%$ and $7 \%$, respectively. Whole brains and synaptosomes from cerebral cortex were obtained from different animals in three separate operiments. The concentrations of $T_{3}$ in whole brain and purified synaptosomes are expressed as the means of four experiments \pm the standard errors of the means.

Assay of $\mathrm{T}_{3}$ and $\mathrm{T}_{4}$ was performed without extraction by collecting fractions of the superfusates directly into antibody-coated tubes from the free- $T_{3}$ and free- $T_{4}$ asay kits. The fractions were then concentrated by drying under $\mathrm{N}_{2}$ and diluted with " 0 " standard from the bit. Standards from the kits were diluted 1:1 with supertusion wash buffer. Assays were then performed according to kit protocols. The sensitivities and interassy coefficients of variation for the free- $\mathrm{T}_{3}$ and free- $\mathrm{T}_{4}$ ssays were $15 \mathrm{fg} /$ tube and $23 \mathrm{fg} /$ tube, and $7 \%$ and $8 \%$, respectively.

\section{Reagents}

Reagents ${ }^{125} \mathrm{I}-\mathrm{T}_{3}(1080$ to $1320 \mu \mathrm{Ci} / \mu \mathrm{g})$ and ${ }^{125} \mathrm{I}_{-} \mathrm{T}_{4}(1080$ to $1320 \mu \mathrm{Ci} / \mu \mathrm{g}$ ) were purchased from New England Nuclear Corp. (Boston, MA), and thyroid hormones and general chemicals were obtained from Sigma Chemical Co. (St. Louis, MO) or Fisher Scientific Co. (Raleigh, NC).

\section{RESULTS}

To validate our methods of measuring thyroid hormone levels in brain tissue, we homogenized whole brains from healthy adult male Sprague-Dawley rats assumed to be euthyroid and determined that the concentration of extracted $\mathrm{T}_{3}$ was $1.64 \pm 0.16 \mathrm{nmol} / \mathrm{L}$ (mean $\pm \mathrm{SEM}$, $n=4)$, which is in agreement with previous findings (Dratman et al. 1983). Then, we determined the concentration of $\mathrm{T}_{3}$ after extraction of the synaptosomal fraction from cerebral cortex obtained by ultracentrifugation. In this fraction, $\mathrm{T}_{3}$ was also present at a concentration of $14.6 \pm 1.4 \mathrm{nmol} / \mathrm{L}$ (mean $\pm \mathrm{SEM}, n=4$ ). In addition, $\mathrm{T}_{3}$ was present in the nuclear pellet containing cell debris and nuclear material and in the mitochondrial pellet at concentrations of approximately $1.4 \mathrm{nmol} / \mathrm{L}$ and $2.9 \mathrm{nmol} / \mathrm{L}$, respectively.

Because the purification of synaptosomes takes about 2 hours, during which synaptosomes are diluted many fold with fresh buffers several times, we were concerned that some endogenous $\mathrm{T}_{3}$ might be lost by diffusion ( ${ }^{125} \mathrm{I}_{-} \mathrm{T}_{3}$-loaded synaptosomes suspended in 20 volumes of superfusion wash buffer lost about $35 \%$ of their radioactivity after an incubation of only 15 minutes at $22^{\circ} \mathrm{C}$ ). Therefore, to simulate presumptive in vivo conditions, where central $\mathrm{T}_{3}$ is constantly replenished from peripheral stores of $T_{4}$ and $T_{3}$, we added $\mathrm{T}_{3}(1 \mathrm{nmol} / \mathrm{L})$ to buffers used in the synaptosome purification. Under this condition, we then found that the concentration of $T_{3}$ extracted from these synaptosome preparations was $63.5 \pm 11.4 \mathrm{nmol} / \mathrm{L}$ (mean \pm SEM, $n=4$.).

In the first set of superfusion experiments, we observed depolarization-induced release of radioactivity from tissues preloaded with ${ }^{125} \mathrm{I}-\mathrm{T}_{3}$ (Fig. 1). A statistical analysis comparing the mean areas under the curves by a two-tailed Student's $t$-test showed that significantly more ${ }^{125} \mathrm{I}-\mathrm{T}_{3}$ was released when $\mathrm{Ca}^{2+}$ was present in the $55-\mathrm{mmol} / \mathrm{L} \mathrm{K}^{+}$release buffer than when it was omitted $(t=2.92, p<0.05)$. These data suggested that the release was initiated by a $\mathrm{Ca}^{2+}$-dependent process. Then, we showed that $85.1 \pm 3.9 \%$ (mean \pm SEM, $n=3$ ) of the released radioactivity was bound by $\mathrm{T}_{3}$ antibody-coated RIA tubes, confurming that it was predominantly ${ }^{125} \mathrm{I}-\mathrm{T}_{3}$ rather than a metabolite of ${ }^{125} \mathrm{I}_{-} \mathrm{T}_{3}$ or free- ${ }^{125} \mathrm{I}$. We found no depolarization-induced release 


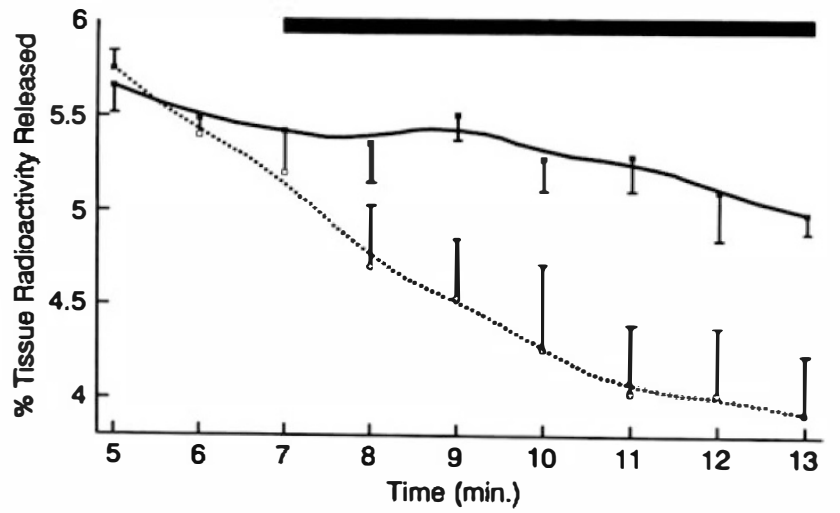

Figure 1. Depolarization-induced release of ${ }^{125} \mathrm{I}-\mathrm{T}_{3}$ from synaptosome-containing homogenates of rat cerebral cortex in the presence ( $\square$ ) and absence $(\square)$ of $\mathrm{Ca}^{2+}$ at $37^{\circ} \mathrm{C}$. Homogenates were superfused with low $(5 \mathrm{mmol} / \mathrm{L}) \mathrm{K}^{+}$ buffer, then superfused with high $(55 \mathrm{mmol} / \mathrm{L}) \mathrm{K}^{+}$depolarization (release) buffer $(\square)$. This figure represents four separate experiments that showed ${ }^{125} \mathrm{I}-\mathrm{T}_{3}$ was released primarily by a $\mathrm{Ca}^{2+}$-dependent process. Each point represents a mean with standard error bars. See text for experimental details.

of radioactivity from tissues that had been preloaded with ${ }^{125} \mathrm{I}_{-} \mathrm{T}_{4}$.

Next, we demonstrated that endogenous $T_{3}$, like ${ }^{125} \mathrm{I}_{-} \mathrm{T}_{3}$, was also released from depolarized synaptosomes primarily by a $\mathrm{Ca}^{2+}$-dependent process (Fig. 2). A statistical comparison of the mean areas under the curves by a two-tailed Student's $t$-test confirmed that more endogenous $\mathrm{T}_{3}$ was released when $\mathrm{Ca}^{2+}$ was present in the release buffer $(t=6.75, p<0.01)$. Only about $20 \%$ of the amount of endogenous $T_{3}$ released in the presence of $\mathrm{Ca}^{2+}$ was released when $\mathrm{Ca}^{2+}$ was omitted from the release buffer (Fig. 2). During the 7 -minute depolarization, $4.8 \% \pm 0.5 \%$ (mean \pm SEM, $n=3$ ) of total endogenous $T_{3}$ was released in the presence of $\mathrm{Ca}^{2+}$.

\section{DISCUSSION}

Based in part on the structural similarity between iodothyronines and the catecholamines, Dratman (1974) hypothesized that thyroid hormones may act as neurotransmitters. Dratman and associates (Dratman et al. 1976; Dratman and Crutchfield 1978) subsequently showed that radiolabeled $\mathrm{T}_{4}$ and $\mathrm{T}_{3}$ intravenously administered to live animals were preferentially taken up into the synaptosomal fraction obtained from rat brain, where $T_{4}$ was also converted to $T_{3}$. In the present study we have demonstrated what was suggested by these earlier isotopic studies: that concentrations of endogenous $\mathrm{T}_{3}$ are much higher in synaptosomes than in whole brain.

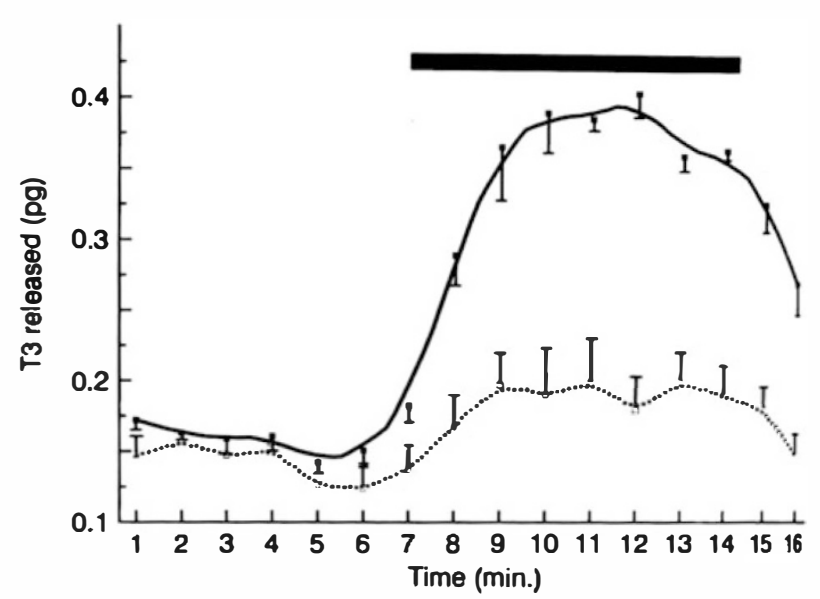

Figure 2. Depolarization-induced release of endogenous $T_{3}$ from synaptosome-containing homogenates of rat cerebral cortex in the presence $(\square)$ and absence $(\square)$ of $\mathrm{Ca}^{2+}$ at $37^{\circ} \mathrm{C}$. Homogenates were first superfused with low $(5 \mathrm{mmol} / \mathrm{L}) \mathrm{K}^{+}$ buffer, then superfused with high $(55 \mathrm{mmol} / \mathrm{L}) \mathrm{K}^{+}$depolari zation (release) buffer $(\square)$. This figure represents three separate experiments that showed $\mathrm{T}_{3}$ was released primarily by a $\mathrm{Ca}^{2+}$-dependent process. Each point represents a mean with standard error bars. See text for experimental details.

Kastellakis and Valcana (1989) reported that $T_{3}$ was actively transported into rat brain synaptosomes by a sodium-dependent process, whereas $\mathrm{T}_{4}$ entered primarily by diffusion. They also showed that ${ }^{125} I_{-} T_{3}$ could be released by homoexchange with nonphysiologic $(10 \mu \mathrm{mol} / \mathrm{L})$ concentrations of unlabeled $\mathrm{T}_{3}$; how. ever, they did not report on depolarization-induced release. In the present study we demonstrated $\mathrm{Ca}^{2+}$. dependent, depolarization-induced release of ${ }^{125}-\mathrm{T}_{3}$ by synaptosome-containing homogenates of rat cerebral cortex using a superfusion system. Using highly sensitive commercial RIAs, we measured $T_{3}$ and $T_{4}$, in superfusates, thereby showing that endogenous $T_{3}$ but not $\mathrm{T}_{4}$ was released by the same process. It is of interest that a much smaller amount of $T_{3}$ was released when $\mathrm{Ca}^{2+}$ was deleted from the high $\mathrm{K}^{+}$depolanza. tion buffer. This release may have been triggered by a process involving intracellular rather than extracellu. lar $\mathrm{Ca}^{2+}$, or by reversal of the proposed $\mathrm{Na}^{+}$-coupled $\mathrm{T}_{3}$ uptake transporter to release $\mathrm{T}_{3}$ from the cytoplasm (Erecinska 1987; Nicholls 1989).

We observed no release of ${ }^{125} \mathrm{I}-\mathrm{T}_{4}$ or endogenous $\mathrm{T}_{4}$ from depolarized synaptosomes. Although our fref $T_{4}$ RIA is extremely sensitive, it is possible that $T_{4}$ was released in minute amounts that we were unable to de tect. However, such small amounts would probably not be of physiologic importance. Perhaps a more plausi. ble explanation is that $T_{4}$ was not released because it was not taken up by putative release vesicles, or it was taken up but converted to $T_{3}$. Some $T_{3}$ may have been released from cytoplasmic stores by transporter rever. 
difollowing depolarization; however, we would not apect $T_{4}$ to be released in this way because it does not otter the synaptosome by a $\mathrm{Na}^{+}$-coupled transporter Nastellakis and Valcana 1989).

Our group showed previously that low nanomob concentrations of $T_{3}$ will enhance depolarizationinduced $\mathrm{Ca}^{2+}$ uptake (Mason et al. 1990) and release of the neurotransmitter gamma-aminobutyric acid (Hashmoto et al. 1991). However, the physiologic relevance dithese actions has remained equivocal, in part because the presence of $\mathrm{T}_{3}$ at presumptive sites of actions has ot been demonstrated. Although we still are unable odirectly measure endogenous $\mathrm{T}_{3}$ concentrations in thesynapse, the present study demonstrates a mechaiism whereby $T_{3}$ concentrations in the synapse can rechlevels that can enhance $\mathrm{Ca}^{2+}$ uptake and release da typical neurotransmitter.

We have shown that endogenous $T_{3}$ is concentated in presynaptic nerve terminals where the cellurrapparatus mediating its active uptake, its synthesis from $T_{4}$, and its degradation are also located. The relase of $T_{3}$, a peripheral hormone, from synaptosomes by $\mathrm{Ca}^{2+}$-dependent depolarization satisfies yet another criterion (Erulkar 1989) for a central neurotransmitter. What remains to be shown is a specific, receptormediated, postsynaptic effect of $T_{3}$. If $T_{3}$ does indeed prove to be a central neurotransmitter, it is surely an musual one; it is readily absorbed by the gut and as readily enters the brain. Thus, given the value of $T_{3}$ as madjunct to tricyclic antidepressants, the iodothyronine molecule may provide a model for the construcion of useful drugs.

\section{ACKNOWLEDGMENTS}

This work was supported by Department of Health and Hum Services Grants MH-33127 and MH-22536 and the Foundetion of Hope for Research and Treatment of Mental Ilness. We are grateful to Ms. Betsy Shambley for preparation d this manuscript.

\section{REFERENCES}

Augustine GJ, Charlton MP, Smith SJ (1987): Calcium action in synaptic transmitter release. Annu Rev Neurosci 10:633-693

Gantz FR, Silva JE, Larsen PR (1982): An analysis of the sources and quantity of 3,5,3'-triiodothyronine specifcally bound to nuclear receptors in rat cerebral cortex and cerebellum. Endocrinology 110:367-375

Dodd PR, Hardy JA, Oakley AE, Edwardson JA, Perry EK, Delaunoy J-P (1981): A rapid method for preparing synaptosomes: Comparison with alternative procedures. Brain Res 226:107-118

Dratman MB (1974): On the mechanism of action of thyroxin, an amino acid analog of tyrosine. J Theor Biol 46:225-270
Dratman MB, Crutchfield FL (1978): Synaptosomal ${ }^{125} \mathrm{I}-$ triiodothyronine following intravenous ${ }^{125} \mathrm{I}$-thyroxine. Am J Physiol 235:E638-E647

Dratman MB, Crutchfield FL, Axelrod J, Colburn RW, Thoa N (1976): Localization of triiodothyronine in nerve ending fractions of rat brain. Proc Natl Acad Sci USA 73:941-944

Dratman MD, Crutchfield FL, Gordon JT, Jennings AS (1983): Iodothyronine homeostasis in rat brain during hypo- and hyperthyroidism. Am J Physiol 245:E185-E193

Erecinska M (1987): The neurotransmitter aminoacid transport systems. Biochem Pharmacol 36:3547-3555

Erulkar SD (1989): Chemically mediated synaptic transmission: an overview. In Siegel G, Agranoff B, Albers RW, Molinoff P (eds). Basic Neurochemistry 4th Ed. New York, Raven Press, pp 151-182

Goodwin FK, Prange AJ Jr, Post RM, Muscettola G, Lipton MA (1982): Potentiation of antidepressant effects by L-triiodothyronine in tricyclic nonresponders. Am J Psychiatry 139:34-38

Hashimoto H, Walker CH, Prange AJ Jr, Mason GA (1991): The effects of thyroid hormones on potassium-stimulated release of ${ }^{3} \mathrm{H}-\mathrm{GABA}$ by synaptosomes of rat cerebral cortex. Neuropsychopharmacology 5:49-54

Kastellakis A, Valcana T (1989): Characterization of thyroid hormone transport in synaptosomes from rat brain. Mol Cell Endocrinol 67:231-241

Lowry OH, Rosebrough NJ, Farr AL, Randall RJ (1951): Protein measurement with the Folin phenol reagent. J Biol Chem 193:265-275

Mashio $Y$, Inada $M$, Tanaka K, Ishii H, Naito K, Nishikawa M, Takahashi K, Imura H (1982): High affinity 3,5,3'-Ltriiodothyronine binding to synaptosomes in rat cerebral cortex. Endocrinology 110:1257-1261

Mashio $Y$, Inada $M$, Tanaka K, Ishii $H$, Naito K, Nishikawa M, Takahashi K, Imura H (1983): Synaptosomal T 3 binding sites in rat brain: Their localization on synaptic membrane and regional distribution. Acta Endocrinol 104: 134-138

Mason GA, Walker CH, Prange AJ Jr (1987): Modulation of GABA uptake of rat brain synaptosomes by thyroid hormones. Neuropsychopharmacology 1:63-69

Mason GA, Walker CH, Prange AJ Jr (1990): Depolarizationdependent ${ }^{45} \mathrm{Ca}$ uptake by synaptosomes of rat cerebral cortex is enhanced by L-triiodothyronine. Neuropsychopharmacology 3:291-295

Nejad I, Bollinger J, Mitnick MA, Sullivan P, Reichlin S (1985): Measurement of plasma and tissue triiodothyronine concentration in the rat by radioimmunoassay. Endocrinology 96:773-779

Nicholls DG (1989): Release of glutamate, aspartate, and $\gamma$-aminobutyric acid from isolated nerve terminals. J Neurochem 52:331-341

Oppenheimer JH (1989): Thyroid hormone action at the cellular level. Science 203:971-979

Prange AJ Jr, Wilson IC, Rabon AM, Lipton MA (1969): Enhancement of imipramine antidepressant activity by thyroid hormone. Am J Psychiatry 126:457-469

Schwarcz G, Halaris A, Baxter L, Escobar J, Thompson M, Young M (1984): Normal thyroid function in desipramine 
nonresponders converted to responders by the addition of L-triiodothyronine. Am J Psychiatry 141:1614-1616

Sterling KN (1979): Thyroid hormone action at the cell level. N Engl J Med 300:117-123, 173-177
Tanaka K, Inada M, Ishii H, Naito K, Nishikawa M, Mashio Y, Imura H (1981): Inner ring monodeiodination of thyroxine and 3,5,3'-L-triiodothyronine in rat brain. Endocrinology 109:1619-1624 